\title{
Evolución y relato: más allá del neodarwinismo y el diseño inteligente
}

\section{Evolution and Story: Beyond Neo-Darwinism and Intelligent Design}

\author{
MANUEL CRUZ ORTIZ DE LANDÁZURI \\ Universidad de Navarra, Pamplona \\ mcruz@unav.es \\ ORCID: 0000-0002-1043-4879
}

Resumen. Este artículo analiza la evolución desde una perspectiva filosófica, contraponiendo los problemas que suscita tanto el neodarwinismo como la teoría del diseño inteligente. En primer lugar, trato algunos problemas que presenta la teoría sintética desde el punto de vista científico, así como los problemas filosóficos implicados en el neodarwinismo de Dawkins, Dennett, Monod y Ruse. Defiendo que el neodarwinismo, aunque se presente como un relato científico, en realidad es fundamentalmente filosófico, y presenta problemas de fondo que lo hacen difícilmente creíble. Por otro lado, discuto el alcance del diseño inteligente como postura filosófica acerca de la evolución de los seres vivos, mostrando sus problemas. Finalmente, propongo un relato filosófico verosímil acerca de la evolución que pretende ir más allá de la lectura científica de los datos de experiencia.

Palabras clave: Dawkins, Diseño Inteligente, Neodarwinismo, Teoría Sintética de la evolución, verosimilitud.

Abstract. This article analyses evolution from a philosophical perspective, contrasting the problems raised by both Neo-Darwinism and Intelligent Design theory. First, I discuss some of the problems that Synthetic theory presents from a scientific point of view, as well as the philosophical problems involved in the Neo-Darwinism 
of Dawkins, Dennett, Monod and Ruse. I argue that Neo-Darwinism, although presented as a scientific doctrine, is in fact fundamentally philosophical, and presents some important problems that make it difficult to believe. On the other hand, I discuss the scope of intelligent design as a philosophical stance on the evolution of living beings, showing its problems. Finally, I propose a credible philosophical account of evolution that seeks to go beyond a scientific reading of the data of experience.

Keywords: Dawkins, Intelligent Design, Neo-Darwinism, Synthetic theory of evolution, verisimilitude.

\section{Introducción}

El ser humano necesita una respuesta a la pregunta fundamental por el origen: ¿de dónde venimos? La vida, según aproximaciones de la ciencia, apareció hace 3.800 millones de años. ¿Qué ha sucedido desde entonces y cómo han surgido las especies? Ante este problema, la ciencia contemporánea sitúa la evolución como un hecho del que podemos estar bastante ciertos, si bien son todavía objeto de estudio los mecanismos que la harían posible. En este sentido, la pregunta filosófica fundamental que suscita la evolución es si esta se rige por el azar y la selección natural o si hay indicios de otro tipo de fuentes de orden.

En las últimas décadas ha sido objeto de debate la cuestión acerca del alcance del Diseño inteligente (Intelligent Design, $I D$ ) en su pretendido estatuto científico. De este modo ha surgido un claro enfrentamiento entre los principales integrantes de este movimiento y las posturas neodarwinistas partidarias de no admitir más fuente de orden que el azar y la selección natural. El ID pretende ser científico y sustituir la explicación neodarwinista de la evolución por un nuevo modelo en el que tenga cabida la necesidad de afirmar un diseño no reducible a la causación mecanicista natural ${ }^{1}$. El neodarwinismo, por el contrario, podría explicar todo el fenómeno de la vida y la evolución de especies por un mecanismo causal necesario basado en la mutación genética al azar y la selección natural.

1 “El diseño inteligente mantiene que la introducción de inteligencia en los sistemas biológicos es empíricamente detectable” (Dembski 2006, 199). 
En este artículo pretendo explorar si este debate acerca del estatuto científico del $I D$ y del neodarwinismo tiene sentido o no, y tratar de aclarar algunos puntos de esta controversia para generar un relato filosófico verosímil. Trataré en primer lugar de situar los límites explicativos de la teoría sintética de la evolución, así como tratar de delimitar qué es el evolucionismo científico y qué es el neodarwinismo como teoría filosófica que excede el ámbito empírico de la ciencia; en segundo lugar, intentaré aclarar el valor explicativo que puede tener el $I D$ y señalar sus límites; en tercer lugar, propondré un plano de discusión más allá del ámbito empírico de la ciencia en el que es posible elaborar un relato filosófico verosímil que supere el reduccionismo de ambas posturas.

En la búsqueda de una respuesta acerca del origen, pone Platón en los labios de Timeo una sentencia importante: "es conveniente que admitamos acerca de estas cosas un relato verosímil y no buscar más que eso" (Timeo 29d). Acerca de la naturaleza todo lo que podemos hacer es elaborar un relato verosímil, y esa verosimilitud puede ser sometida a crítica racional. En el último apartado defenderé que la verosimilitud del relato, más allá del campo descriptivo de la ciencia, viene dado por los argumentos filosóficos.

\section{Debate neodarwinismo-diseño inteligente}

Es preciso distinguir entre el neodarwinismo como teoría científica y como teoría filosófica. El neodarwinismo como teoría científica supone entender la evolución de los organismos por mutaciones genéticas, sin una pretensión de entender por qué se producen tales mutaciones. El azar como fuente de las mutaciones aparece como un agujero ciego: de hecho se producen mutaciones aleatorias y algunas deben de ser beneficiosas. ¿Por qué se producen estas mutaciones? Lo ignoramos, y esa ignorancia es precisamente lo que llamamos azar. Esta visión del darwinismo como teoría científica se encuentra frente a algunos problemas explicativos importantes, ya que actualmente se ha descubierto la importancia de la epigenética, la regulación de los genes y factores ambientales como factores de evolución. Hay quien sostiene que la principal causa de evolución no 
sería la mutación en los genes, sino el cambio en la regulación de los genes, que provocaría en el desarrollo embrionario cambios importantes en el fenotipo (Whitfield 2018, 281-284).

Por otro lado, el neodarwinismo como teoría filosófica sostiene que las mutaciones causantes de la evolución se deben al azar, es decir, a la realización aleatoria de probabilidades, de modo que el orden y complejidad de los organismos es el cúmulo de casualidades que han prosperado. En la naturaleza, por tanto, no habría una causa del orden, sino que la naturaleza actuaría como un "relojero ciego". Algunos de los principales representantes de esta visión son Dawkins (1988), Dennett (1999), Monod (1985) y Ayala (2007). Además, aunque algunos teóricos de la biología como E. Mayr (1988) defienden el uso del término “teleología” para el estudio de los procesos orgánicos, sin embargo precisan que esto no debe suponer ninguna propuesta metafísica: no existe ningún plan o una forma de antemano que guíe los procesos (a excepción del ADN, que estaría determinado por las leyes de la bioquímica y las mutaciones al azar). Dicho en otras palabras: los procesos biológicos realizan una función que es el resultado de la selección natural, y el biólogo utiliza la noción de fin para expresar esa función, que en ningún caso supone una adaptación inteligente, sino en todo caso una metáfora (Ruse 2003).

El problema es que a menudo no está clara la diferencia entre el neodarwinismo como explicación científica y como teoría filosófica, en buena medida porque el azar como causante de las mutaciones puede ser interpretado de varias maneras. Se puede invocar el azar como algo que se desconoce pero que sucede con necesidad absoluta (como por ejemplo cuando decimos que si tiro una moneda al aire saldrá cara o cruz de manera azarosa: no sabemos cuál de las dos caras saldrá, pero la moneda se encuentra sometida a las leyes de la física de manera necesaria), también como un conjunto de probabilidades matemáticas que se realizarán a lo largo del tiempo, por otro lado el azar se puede entender como "error" (en el sentido de que debido a sucesos fortuitos se producen "errores" de copia en el ADN), por último como una fuente de resultados aleatorios debido a causas ocultas que desconocemos. 
Por tanto, el quicio del problema está en el modo de entender la palabra azar (Alexander 2020, 18-27). Si el azar se invoca como causa desconocida, entonces es legítimo invocar el azar para señalar el límite cognoscitivo de la ciencia, porque entonces decir que "las mutaciones se producen al azar" equivale a decir que las mutaciones se producen por alguna causa que desconocemos (y que probablemente jamás podamos conocer). Es más, decir esto es señalar que existe una puerta para algo que la ciencia no puede captar (quizás porque excede lo empírico) y dejar una pregunta abierta para la filosofía (que podrá tratar de dilucidar la respuesta por otros caminos). Ahora bien, si el azar se entiende como la realización de probabilidades, entonces se dibuja un relato mecanicista del orden del mundo. En tal caso, decir que "las mutaciones se producen al azar" equivale a decir que se producen porque tienen que producirse en algún momento dado, y que todo lo posible deviene real. Todas las mutaciones posibles se realizarán, y de estas algunas serán favorables a la especie y se perpetuarán en el tiempo. Esta es la visión que parecen compartir Dawkins y Monod.

El gran problema en torno al debate neodarwinismo filosófico-diseño inteligente es que ambas posturas pretenden ser científicas. Los neodarwinistas aducen a su favor que es la mejor explicación científica acerca de la evolución de la vida y la única vía posible para explicar los organismos desde los presupuestos de la explicación mecánica, propia de la ciencia natural. Los partidarios del diseño inteligente afirman que la complejidad irreductible (Behe) y la inferencia del diseño (Dembski) muestran que la ciencia necesita admitir un orden que excede el papel del azar en la evolución. A continuación trataré de mostrar que ni el neodarwinismo como postura filosófica ni el diseño inteligente pueden proporcionar un relato verosímil acerca del origen de las especies y la evolución de la vida. Para ello examinaré si son posturas realmente científicas y por último trataré de proponer un relato verosímil. 


\section{2. ¿Es el neodarwinismo una postura científica?}

Para los partidarios del neodarwinismo, esta teoría se presenta como la única alternativa razonable para explicar la evolución de la vida desde el punto de vista científico. Es decir, si hay evolución en las especies, esta evolución debe responder a un mecanismo natural. Como la única fuente de cambio conocida en el ADN son las mutaciones aleatorias que se producen al originarse un nuevo individuo, entonces deben ser estas las causantes de los cambios en las especies. Después, la selección natural hace que aquellas mutaciones favorables se transmitan a lo largo de las generaciones a la especie y esta vaya evolucionando.

El neodarwinismo se presenta así como la consecuencia lógica de la teoría sintética de la evolución. A menudo se han identificado estas dos posturas, pero resulta conveniente hacer una matización importante. La teoría sintética consiste en la combinación de la evolución de Darwin con la teoría genética y las leyes de la herencia de Mendel para explicar la evolución de las especies, pero ella en sí misma no implica un relato filosófico, sino únicamente científico (Artigas 1992, 300). La teoría sintética es una teoría científica que puede funcionar para algunos casos, como por ejemplo, la mutación de la hemoglobina, la lactasa, etc. Sin embargo, la teoría sintética tiene problemas para poder explicar los grandes cambios en las especies. Por eso, recientemente se ha propuesto que en realidad la clave no estaría tanto en la modificación del ADN como en el modo de expresarse en los primeros días y semanas de desarrollo embrionario. Por ejemplo, los estudios de Evo-Devo (Evolution and Development), aunque se encuentran todavía en una fase inicial, han mostrado que la teoría sintética de la evolución debe ser completada con el estudio de la expresión de los genes en distintos momentos del desarrollo, que es la causa de las variaciones fenotípicas (Laublicher y Maienschein 2009). Por otro lado, hay científicos que se muestran partidarios de incluir mecanismos hereditarios epigenéticos (relativos a la expresión de los genes) entre las causas principales de la evolución: incluso algunos piensan que ciertas variaciones epigenéticas hereditarias responden a una función adaptativa (Jablonka-Lamb 2005, 140-145). En cualquier caso, todavía podría man- 
tenerse que ese cambio en el modo de expresión ha sido azaroso, de modo que el orden en las especies y la vida es producto del azar y la necesidad.

Entre los defensores de la visión neodarwinista destaca Richard Dawkins, que en su libro El relojero ciego sale al paso de las críticas que se suelen hacer al darwinismo como explicación científica y filosófica. Frente a los que objetan la poca probabilidad de que surgieran organismos complejos (teniendo en cuenta el tiempo de la tierra y el universo), Dawkins aduce que no hay que entender la evolución en una sola etapa, sino como un proceso acumulativo, en el que las pequeñas variaciones favorables se conservan (Dawkins 1988, 38). De este modo muestra cómo a un mono no le costaría demasiado llegar a escribir una determinada frase por combinaciones azarosas, siempre y cuando se conservaran las coincidencias. Sin embargo, la analogía presenta problemas importantes, ya que nosotros sabemos cuál es la frase que el mono tiene que escribir y qué letras hay que conservar para que la frase tenga sentido (es decir, para que un organismo funcione). Ahora bien, si el relojero es ciego no sabe cuál es la frase que hay que escribir para que tenga sentido, y por lo tanto no sabe cómo acumular variaciones que permitan que el organismo funcione.

Se podrá decir que lo único importante es que haya frases legibles (cambios genotípicos que lleven a cambios en el fenotipo), y que luego se le encontraran el sentido (la función), pero también en este caso hay que considerar que no cualquier combinación de letras hace posible una frase: se necesita un mínimo orden. Si las combinaciones de letras no tienen sentido en su proceso de construcción, entonces habría que empezar de cero cada frase: no bastan las coincidencias, tiene que haber una frase con sentido. Volviendo a la bioquímica: no basta con cualquier combinación de bases, sino que estas deben de tener la capacidad de expresar una proteína. Imaginemos que el mono tuviese que escribir al frase: "quiero un plátano". No basta con que escriba "qjwerupuf paetaxm" para que eso signifique algo. Para que haya un significado tiene que haber un mínimo de letras combinadas que sean traducibles en un significado. En otras palabras, o el azar produce una frase con un mínimo significado de una sola vez o no sirve para nada. Para Dawkins esto no sería un gran problema, ya que desde su perspectiva el azar terminará produciendo alguna modifi- 
cación favorable. Precisamente por eso el núcleo de la propuesta de Dawkins, desde el punto de vista filosófico, se encuentra en la necesidad de la posibilidad lógica. Dice Dawkins: "Mi idea es que, siempre que la diferencia entre los intermediarios vecinos de nuestra serie que conduce al ojo sea suficientemente pequeña, las mutaciones precisas están casi obligadas a aparecer" (Dawkins 1988, 60).

Si es posible imaginar una serie de pasos intermedios, entonces es posible que se haya dado el proceso a lo largo de generaciones. Si es posible que surjan mutaciones precisas, entonces es que necesariamente se han dado. Sin embargo, aquí estamos ante un argumento que pasa de la posibilidad lógica a la posibilidad real. Yo me puedo imaginar el proceso, pero eso no significa que se haya dado (cuestión distinta es que puedo encontrar evidencias, como versiones más simples del ojo en otros seres vivos, que sugieran que se haya dado) y, todavía más grave, puedo imaginar que se han producido las mutaciones precisas, pero no lo puedo demostrar o, en todo caso, no puedo asegurar que se deban al azar (al relojero ciego).

La pregunta clave no es si el ojo pudo evolucionar a través de pequeñas variaciones, sino si estas se han podido deber al azar. Para ello hay que atribuir a los organismos un poder de mutación asombroso pues, como dice Dawkins, "las mutaciones precisas están obligadas a aparecer”. Eso significa que los organismos realizan todas las posibilidades, lo cual es una hipótesis muy difícilmente demostrable. Es más, el propio Dawkins admite al final de su libro que en realidad las mutaciones genéticas se concentran sobre todo en unos genes, y no en otros. Si esto es así, y al menos lo que se observa es que esas mutaciones producen casi siempre enfermedades, resulta muy difícil asentar en hechos evidentes que las mutaciones precisas están obligadas a aparecer (al menos mientras el relojero sea ciego). Quedará siempre la posibilidad lógica en nuestras cabezas, pero la posibilidad lógica es solo aquello que no implica contradicción (por ejemplo que exista un unicornio es posible, porque desde el punto de vista lógico no es contradictorio), y la posibilidad lógica no implica nunca la existencia de algo (que yo pueda concebir un unicornio y su evolución a partir del caballo no significa que exista un unicornio en una isla todavía sin explorar). 
Sucede lo mismo en el ejemplo de las golondrinas que utiliza al comienzo del libro:

Las golondrinas vuelan. Como hemos visto, no es fácil construir una máquina voladora. Si se observan las células de una golondrina, y se colocan juntas al azar, la probabilidad de que el objeto resultante vuele no es, para nuestros propósitos, distinta de cero. No todos los seres vivos vuelan, pero hacen otras cosas que son igualmente poco probables (Dawkins 1988, 6).

Igual que la disposición de las rocas del Montblanc era poco probable pero es una probabilidad hecha realidad, de igual modo, que las golondrinas vuelen es algo muy poco probable, pero de hecho lo hacen. Por lo tanto esa probabilidad se ha realizado. La pregunta entonces es por qué se ha realizado esa probabilidad. La respuesta de Dawkins es que simplemente se realizó, y punto. Lo que pasa entonces es que una cosa es la probabilidad matemática y otra la probabilidad real. El que los elementos se unan y casualmente surjan -a lo largo del tiempo- organismos complejos es algo posible (desde el punto de vista lógico, ya que no implica contradicción), pero no está claro que sea una posibilidad realizable, porque los elementos, al menos hasta donde conocemos actualmente, no tienen el poder de organizar sistemas complejos. El Montblanc no es ningún sistema complejo, es únicamente un cúmulo de elementos dispuestos por las leyes de la física. La golondrina, sin embargo, es un sistema dinámico formado por partes que interactúan en el tiempo: un sistema complejo.

En realidad el argumento de fondo de Dawkins es circular. Dice: dado que hay especies constituidas y existe el mecanismo de mutación y la selección natural, entonces las especies constituidas se explican solo con este mecanismo simple. Ahora bien, esto solo se podría asumir si de hecho pudiésemos saber que éste es el único mecanismo que opera en la vida, a lo que Dawkins dice: sí, es el único mecanismo, la prueba de ello son la diversidad de especies constituidas. Pero este argumento no funciona, porque no es lícito atribuir como prueba aquello que se quiere probar (explicar). El punto crucial sería poder explicar cómo pueden surgir máquinas complejas -organismos irreductiblemente complejos- por acumulación de pequeñas variaciones al azar. La respuesta de Dawkins es que 
se pueden explicar porque de hecho se dan. Pero esta no es ninguna explicación, y en este punto es donde el relato pierde cierta verosimilitud. El razonamiento es el siguiente:

- Podría suceder (con mínima probabilidad).

- De hecho ha sucedido (existen especies).

- Por lo tanto todo se explica por mutación y selección natural.

Pero el problema es que el primer "suceder" y el segundo no se refieren a lo mismo. Decir que la evolución podría haber sucedido de acuerdo a la mutación y selección natural significa que no hay imposibilidad lógica en que eso suceda. Hay una remotísima posibilidad, igual que es posible que existan unicornios en alguna isla que todavía no hemos descubierto. Pero se dirá: el mecanismo de variación existe y opera. Cierto, pero hasta el momento solo parece que se pueden explicar microevoluciones muy puntuales mediante ese mecanismo.

Por otro lado, los sistemas irreductiblemente complejos son también un problema real para el neodarwinismo, al menos desde el punto de vista filosófico. Por ejemplo, hoy sabemos que para producir una proteína específica hacen falta otras proteínas que permiten la traducción del gen específico en ARN y posterior ensamblaje en el ribosoma. Esas otras proteínas se encuentran codificadas también en el ADN, y así sucesivamente. Si lo pensamos a su vez desde el punto de vista del desarrollo embrionario, resulta que los genes se encuentran regulados para que se activen en situaciones muy específicas. Todo esto nos muestra que el organismo es un sistema complejo que queda totalmente sin explicar aduciendo mutaciones al azar. No se debe olvidar que las mutaciones al azar son en la mayoría de casos errores de copia. ¿Cómo podría surgir el orden por una acumulación de errores? Si esto es así habría que explicarlo de modo detallado porque, como se ha visto anteriormente, la mera posibilidad lógica no supone la necesidad real.

Para concluir este apartado se podría decir que el argumento neodarwinista, en líneas generales, es el siguiente: dado que solo hay materia, las especies evolucionan por pequeños cambios azarosos en la materia. Sin embargo, este relato presupone de antemano aquello que se quiere demostrar: que lo único relevante para explicar la vida es la materia en- 
tendida como átomos. Todo orden es fortuito y a la vez necesario. Afirma Dennett: “Todos sabemos una cosa: no podemos hacer una revolución científica a partir de una corazonada que casi no puede someterse a prueba” (Dennett 199, 501). Siguiendo su misma línea de razonamiento podríamos decir que no se puede constituir el neodarwinismo filosófico en un relato verosímil (y mucho menos en una teoría científica) partiendo de una corazonada (las mutaciones azarosas como fuente de orden) que casi no puede someterse a prueba. Es más, cada vez se descubren nuevos factores epigenéticos hereditarios que parecen poner en jaque un relato neodarwinista centrado en el cambio azaroso en los genes (Jablonka-Lamb 2005, 144-145).

\section{El diseño inteligente y sus problemas}

Vistos los problemas de verosimilitud del relato neodarwinista, podemos examinar el otro punto de vista, aquel que afirma que es posible detectar diseño inteligente en la naturaleza. Si hay un orden que no se puede explicar por pequeñas acumulaciones azarosas, entonces es que estamos ante un diseño, y en último término podríamos admitir que alguien o algo ha tenido que generar ese diseño. Entre los principales defensores del diseño inteligente se encuentran el bioquímico Michael Behe y el matemático William Dembski. El argumento de Behe en su libro La caja negra de Darwin es que la teoría darwiniana no puede explicar la base molecular de la vida. Para ello examina varios ejemplos de lo que él llama "complejidad irreductible” en la célula: estructuras que no se habrían podido generar por simple agregación de pequeñas variaciones:

Si un sistema requiere de varias partes armónicas para funcionar, es irreductiblemente complejo, y podemos llegar a la conclusión de que se produjo como una unidad integrada (Behe 1999, 70).

Behe no niega la evolución (1999, 22), sino la posibilidad de que los mecanismos darwinianos puedan explicar la realidad de sistemas complejos. El modo de ver esto es mostrar que hay un diseño evidente cuando "una 
cantidad de componentes autónomos e interactuantes están ordenados de tal modo que cumplen una función que trasciende los componentes individuales" (1999, 241).

El libro de Behe ofrece ejemplos y argumentos muy bien armados. Sale al paso de críticas complicadas, como las imperfecciones de diseño en la naturaleza. Si hay diseño en la naturaleza y por lo tanto un diseñador, ¿por qué hay imperfecciones? La respuesta de Behe es que una cosa es que se pueda detectar diseño y otra que el diseño sea todo lo óptimo que nosotros podamos pensar ${ }^{2}$. Sin embargo, llegados a este punto parece que el relato del diseño inteligente presenta el problema de querer demostrar demasiado. "El resultado de estos esfuerzos acumulativos para investigar la célula es un estridente y penetrante grito de ¡Diseño!” (1999, 275-277). Una cosa es demostrar que la bioquímica trabaja con el paradigma de diseño y otra que el diseño sea el producto de una inteligencia. La bioquímica puede mostrar cómo son los procesos y su complejidad, puede describir la vida "como si" hubiese diseño, pero a la bioquímica no le compete establecer si el diseño en la naturaleza es producto del azar o de un diseñador inteligente. A lo más que podría llegar la bioquímica es a mostrar que el diseño no ha podido surgir únicamente por azar. En este sentido, el gran mérito de Behe estriba en haber puesto de manifiesto los límites explicativos del neodarwinismo. Ahora bien, su postura tiene el problema de que trata de armar un relato acerca del diseño basado en pruebas científicas, cuando es posible señalar (al menos desde el punto de vista biológico) la formación de sistemas complejos a través de pequeñas variaciones. Behe piensa que el azar (entendido como meros sucesos fortuitos) no puede generar el orden y, aunque yo me pueda imaginar un posible proceso de pequeñas variaciones, eso no podría haber generado un sistema complejo. Sin embargo, como señala Ruse (2003, 320), uno podría imaginar que en estos sistemas complejos sucede algo análogo a la construcción de un puente: sobre una estructura previa se desarrollan procesos y partes con distintas funciones que en algún momento se autoensamblan, sin necesitar ya del soporte. Ruse encuentra ejemplo de esto en la constitución del ciclo de Krebs (Ruse 2003, 321). Aunque todavía se podría reivindi-

2 Behe, M. J., La caja negra de Darwin, Andrés Bello, Barcelona, 1999, pp. 275-277. 
car que una cosa es la pregunta por el proceso que ha formado el sistema complejo (se podría explicar con la analogía del puente) y otra distinta la pregunta por la causa del proceso (¿se forma el ciclo de Krebs por variaciones al azar?), el caso es que podrían darse sistemas complejos en pasos graduales. En este sentido, no parece posible deducir que es imposible que se formen sistemas complejos por pequeños cambios. Es muy difícil e improbable, pero existe una mínima posibilidad que no se puede ignorar. La pregunta en todo caso sigue estando en torno a la causa de esos cambios.

Por otro lado, Dembski ha sido el más claro sistemático y formulador del diseño inteligente como postura científica (Dembski 2006). Aunque presenta argumentos poderosos en contra del azar como fuente de orden e información, sin embargo critica el darwinismo en general sin descender de modo claro a los representantes de tal postura. En líneas generales parece que Dawkins es el objeto de sus críticas, pero no lo deja del todo claro. De este modo quizás cae en la estrategia que él mismo critica a los darwinistas, el haber creado un enemigo difuso conceptualmente y, por lo tanto, fácilmente atacable. Por otro lado, al pretender hacer del diseño inteligente una postura científica, parece convertirlo en un movimiento ideológico que debe impregnar la ciencia más que en una teoría que explique mejor cómo son las cosas. Quizás es posible detectar diseño y orden en biología, pero la pregunta por el diseño y el orden exceden el ámbito de la ciencia (Rhonheimer 2008, 106). El diseño inteligente, al pretender demostrar el diseño de manera empírica, excede lo que la ciencia empírica puede demostrar.

Sin embargo, no siempre los críticos del diseño inteligente han sido afortunados en su crítica. Por ejemplo, Ayala en su defensa del darwinismo azaroso y la selección natural llega a asumir posiciones un tanto contradictorias:

La evolución no está gobernada por mutaciones fortuitas. Más bien hay un proceso natural (es decir, una selección natural) que no es aleatorio, sino orientado y capaz de generar orden y crear. Los rasgos que los organismos adquieren en sus historias evolutivas no son fortuitos, sino que están determinados por su utilidad funcional para los organismos [...]. Sin embargo, el azar es una parte integral del proceso evolutivo. Las mutaciones que producen las 
variaciones hereditarias disponibles para la selección natural surgen al azar (Ayala 2007, 85).

Ayala quiere defender que las mutaciones se producen por azar y a la vez establecer que la evolución tiene un orden (debido a la selección natural). Pero la selección natural no es por sí misma causante de orden. Decir eso sería tanto como decir que el orden que vemos en realidad es aparente, es pura necesidad, golpe de suerte, como dice Monod (1985). Ayala confunde el hecho de ser irreductiblemente complejo con el hecho de que haya podido evolucionar. La cuestión en juego es si por cambios azarosos puede surgir un sistema que funcione (y que pueda evolucionar). La pregunta es por la causa, no por el proceso. El problema del relato del diseño inteligente no está, por tanto, en aquello que se defiende (la necesidad de una causa del orden), sino en el modo de defenderlo, al tratar de justificar la causa del orden desde el punto de vista de la ciencia naturalista. El diseño inteligente intenta buscar un tipo de explicación más allá del método científico naturalista partiendo de las explicaciones de la ciencia naturalista: de este modo, resulta imposible que pueda llegar a demostrar nada que exceda el ámbito de la ciencia natural. Si entiendo que la naturaleza es un conjunto de procesos mecánicos, siempre toparé con un proceso mecánico como modo de explicación, nunca "encontraré" una fuente de orden que no sea material y mecánica.

El diseño inteligente no puede ser una teoría científica, porque no tiene valor predictivo alguno. El hecho de que haya diseño en los organismos no sirve de mucho al científico a la hora de tener que explicar cómo se rige ese diseño, cómo transcurren los procesos bioquímicos (Kitcher 2001). Como mucho el diseño inteligente podría tener algo de valor como "idea regulativa”, ya que la ciencia tiene que operar "como si” hubiera diseño.

\section{Hacia un nuevo relato}

Si algo nos ha enseñado el diseño inteligente es que la búsqueda del relato tiene que ir en una dirección distinta del orden puramente científico. Desde el momento en que la ciencia busca describir procesos, y no pre- 
gunta por otras causas, la pregunta por el relato tiene que remontarse a la filosofía. El problema de fondo es que tanto el neodarwinismo como el diseño inteligente le han pedido demasiado a la ciencia. El neodarwinismo esperaba con una simple teoría naturalista poder explicar todo el fenómeno de la vida. El diseño inteligente pensaba que con mostrar la presencia de organización compleja se podía demostrar la existencia de un diseñador. Pero en realidad ninguno de los relatos son verosímiles porque pecan de entusiasmo en sus premisas. La ciencia lo único que hace es mostrar que los organismos han avanzado en la historia del mundo por evolución. Tanto el diseño inteligente como el neodarwinismo se apoyan en una visión mecanicista del mundo, en la cual algo se explica únicamente en términos descriptivos de las partes y los procesos que integran ese algo (Collado 2008, 38).

Por otro lado, los mecanismos que pueden llevar a un ser vivo a evolucionar son variados: existen mutaciones en el ADN, pero también hay factores epigenéticos, y posiblemente cambios en elementos reguladores de la expresión de los genes que han podido ocasionar cambios importantes en el desarrollo embrionario. En este sentido, la complejidad del organismo se debe en buena medida a adaptaciones y a las condiciones que la gravedad y las leyes del mundo físico imponen sobre la vida. Sin embargo, el ser humano necesita un relato verosímil que vaya más allá de la descripción de los procesos que rigen la vida, y es aquí donde la filosofía puede aportar una luz distinta sobre los fenómenos al estudiar el asunto desde un punto de vista distinto. Ahora bien, ¿cómo debe ser ese relato? La verosimilitud de un relato consiste en la mejor aproximación a la verdad (Popper 1983, 287). En el caso de la filosofía, la verosimilitud del relato, su aproximación a la verdad, viene dada por la calidad de sus argumentos. Ahora bien, resulta claro que ni el mecanicismo darwinista ni el mecanicismo del diseño inteligente ofrecen un relato satisfactorio. El problema de base, como se ha mostrado, está en la presunta capacidad explicativa del modelo mecánico. ¿Y si el pretender que los procesos mecánicos sean toda la explicación de la naturaleza fuese una ilusión reduccionista? Si en la realidad hay información, y la información no puede ser producto de un proceso mecánico aleatorio, entonces es que los procesos 
naturales no son solo mecánicos. Quizás haya una fuente de orden que no se reduce a un único elemento pero que es inteligible en sus manifestaciones. Filósofos como Godfrey-Smith (2001, 587-588) piensan que admitir una fuente de orden más allá de los mecanismos observables es apelar a un "misterio metafísico", cuando en realidad es sencilla metafísica entendida como indagación acerca del fundamento. Lógicamente, no es posible obtener evidencia empírica de esa fuente de orden, precisamente porque excede lo empírico, aunque está presente en los procesos observables. Por eso, es posible obtener evidencia a partir de una visión holística del organismo.

La evolución reconstruye la historia de los organismos mirando la vida desde el pasado. ¿Qué pasa si miramos la vida desde el presente que vivimos? ¿Qué sucede en nuestra intuición directa de la vida? Que esta se presenta como marcha hacia delante, como cambio y creación continua. El problema del neodarwinismo estriba en que al reducir el proceso evolutivo a un único mecanismo (mutación al azar y selección natural) comprende la naturaleza desde un paradigma muy reduccionista, en el cual lo único importante son las partículas de materia (las bases nitrogenadas formadas por átomos) y las interacciones físico-químicas inmediatas. Sin embargo quizás el organismo vivo es más rico que esto, también en sus procesos evolutivos. De hecho muchos biólogos se muestran partidarios de elaborar una nueva teoría evolutiva que incorpore factores ambientales y epigenéticos, quizás incluso mecanismos lamarckianos (Cairns, Overbaugh and Miller 1988, 142-145; Koonin 2019). Es muy probable que los cambios fenotípicos no se deban a cambios genéticos, sino a cambios en la expresión de los genes en determinadas células. Muchas veces los cambios microevolutivos tienen que ver más con la ausencia de represión de genes que ya existían y que permiten la producción de enzimas que no se habían estado produciendo hasta entonces (Gould 1977, 406). Pero, en cualquier caso, la ciencia siempre será un relato descriptivo, y no le corresponde a ella deducir la finalidad. Como señala Gilson (1976, 297), la cuestión de la finalidad le corresponde a una filosofía finalista responsable de sí misma, que no tiene por qué comprometer para nada a la ciencia. La cuestión de la finalidad viene dada por una aprehensión casi intuitiva 
de la observación de la naturaleza, de modo que "si se rechaza la finalidad como explicación, subsiste como hecho a explicar" (Gilson 1976, 300).

El relato que quiero ofrecer, desde el punto de vista filosófico, es el siguiente: evolución sí, diseño sí y azar también. Hay que entender la naturaleza como un proceso en el que los organismos se han autoorganizado en formas estables en el tiempo, que incorporan variaciones, a veces debido al azar, a veces debido a cambios adaptativos, posiblemente también a través de un impuso vital que no podemos observar empíricamente pero que podemos intuir en nuestra percepción contemplativa del mundo. Los organismos aparecen como formas arquitectónicas en las que soluciones geniales se combinan con arreglos puntuales para problemas determinados. No todo puede ser producto del azar en el sentido de la determinación de las leyes físico-químicas. El orden tampoco puede surgir por acumulación de errores. En este sentido, debemos admitir que la naturaleza es algo más que puros procesos mecánicos explicables únicamente desde las partes que lo integran. Los organismos son, fundamentalmente, unidades vivas, solamente comprensibles como un todo. La evolución de los organismos debe tener una causa más profunda que las puras mutaciones al azar, puesto que estas por sí solas (sin un principio unificador) no podrían generar estructuras complejas e interacciones entre los organismos.

Este es un punto que no podrá ser admitido por quien busque un relato científico mecanicista. Por ejemplo, el filósofo Michael Ruse rechaza el vitalismo porque cree que si una idea (como el élan vital de Bergson) no tiene valor predictivo, entonces no tiene valor explicativo alguno. Explicar para Ruse es poder predecir, dar cuenta del mecanismo. Sin embargo, ¿explicar no es también comprender, basándose en razones? ¿No estará Ruse atrapado en el paradigma descriptivo de la ciencia mecanicista? Por otro lado, el propio Ruse cae en una severa contradicción al asignar al neodarwinismo basado en mutaciones aleatorias un poder predictivo que no posee (Ruse 2003, 255). En realidad, si el neodarwinismo tiene valor como relato es porque ofrece una explicación comprensiva de los organismos, y no por su valor predictivo (no puede predecir cómo van a evolucionar los organismos). En el fondo, el neodarwinismo hace de las mutaciones aleatorias un tipo de entelequia ciega capaz de generar todo, la 
gran protagonista del relato. $\mathrm{O}$ bien se asume que las mutaciones aleatorias son una manera de señalar nuestra ignorancia científica acerca del origen de la evolución (y entonces habrá que buscar un relato filosófico verosímil), o bien hay que asumir que son una fuente ciega de cambio capaz de explicar el orden del mundo (y se admite un relato materialista con grandes problemas explicativos). Quizás este problema es el que le lleva a Ruse a terminar su libro con una cierta actitud relativista escéptica sobre la posibilidad de alcanzar un relato comprensivo más allá de lo que la ciencia pueda explicar.

La pregunta por el relato depende del punto de vista que se quiera adoptar. Si optamos por ver la naturaleza desde una perspectiva mecanicista, entonces la vida aparece como un proceso pasivo, siendo el golpe fortuito de la necesidad la causa de variaciones, o un diseñador inteligente externo al mundo el que introduce el orden. Ambas respuestas están lejos de ser satisfactorias, en un caso porque no se puede explicar el orden, en otro caso porque no se pueden explicar las imperfecciones. Si optamos por entender la vida como un dinamismo activo constituido por elementos materiales (pero que quizás sea algo más que eso) entonces puede ser que haya algún tipo de fuerza vital que genere orden. Ese "algo más que elementos materiales" no será algo que se pueda ver, ni medir, en ningún caso se podrá postular como "entelequia" desde el punto de vista científico, pero quizás se podrá deducir o quizás intuir a través de la experiencia de la vida como fuerza creativa. Este es un relato verosímil que excede el campo de la ciencia pero que ofrece una respuesta satisfactoria para la reflexión filosófica. Aquí es donde el científico encontrará siempre un límite a su campo de conocimiento:

Yo puedo aceptar las formas abstractas thompsonianas como adaptaciones óptimas, pero en cuanto a la cuestión metafísica más amplia de por qué la «buena» forma a menudo exhibe una regularidad tan sencilla y numérica, no puedo más que alegar mi ignorancia y maravillarme (Gould 1985, 41). 


\section{Referencias}

Alexander, Denis R. 2020. “Is Evolution a Chance Process?”. Scientia et Fides 8 (2): $15-41$.

Artigas, Mariano. 1992. La inteligibilidad de la naturaleza. Pamplona: Eunsa. Ayala, Francisco José. 2007. Darwin y el diseño inteligente. Madrid: Alianza. Behe, Michael. 1999. La caja negra de Darwin. Barcelona: Andrés Bello.

Cairns, J., Overbaugh, J., Miller, S. 1988. “The origin of mutants”. Nature 335: 142-145.

Collado, Santiago. 2008. “Panorámica del «diseño inteligente»”. Acta Philosophica 17: 38.

Dawkins, Richard. 1988. El relojero ciego. Barcelona: Labor.

Dembski, William. 2006. Diseño inteligente. Madrid: Homo Legens.

Dennett, Daniel. 1999. La peligrosa idea de Darwin, Barcelona: Galaxia Gutenberg. Dobzhansky, Theodosius. 1973. "Nothing in Biology Makes Sense Except in the Light of Evolution”. The American Biology Teacher: 125-129.

Gilson, Etienne. 1976. De Aristóteles a Darwin (y vuelta). Pamplona: Eunsa.

Godfrey-Smith, Peter. 2001. “Information and the Argument from Design”. In Intelligent Design and Its Critics, edited by R. T. Pennock, 575-596. Cambridge: MIT Press.

Gould, Stephen. 1977. Ontogeny and Phylogeny. Cambridge: Harvard University Press.

Gould, Stephen. 1985. El pulgar del panda. Barcelona: Orbis.

Jablonka, Eva y Lamb, Marion. 2005. Evolution in Four Dimensions, Cambridge: MIT Press, Cambridge.

Kitcher, Philip. 2001. “Born-Again Creationism”, In Intelligent Design and Its Critics, edited by R. T. Pennock, 257-287. Cambridge: MIT Press.

Koonin, Eugene V. 2019. "Lamarckian or not, CRISPR-Cas is an elaborate engine of directed evolution”. Biology and Philosophy 34, 17. doi: 10.1007/s10539018-9666-7

Laublicher, Manfred, y Maienschein, Jane (eds.). 2009. Form and Function in Developmental Evolution. Cambridge: Cambridge University Press.

Mayr, Ernst. 1988. “The Multiple Meanings of Teleological”. In Toward a New Philosophy of Biology, 38-66. Cambridge: Harvard University Press.

Monod, Jacques. 1985. El azar y la necesidad. Barcelona: Orbis.

Platón. Timeo. Traducción de C. Eggers. 2005. Buenos Aires: Colihue.

Popper, Karl. 1983. Conjeturas y refutaciones. Barcelona: Paidos. 
Rhonheimer, Martin. 2008. “Teoría dell'evoluzione neodarwinista, 'Intelligent design' e creazione. In dialogo con il Cardinal Christoph Schönborn”, Acta Philosophica 17: 87-134.

Ruse, Michael. 2003. Darwin and Design. Cambridge: Harvard University Press. Whitfield, John. 2008. “Postmodern Evolution?”. Nature 455: 281-284. 